\title{
List of Changes
}

Manuscript:

Preparation of layered double hydroxides with different divalent metals for the adsorption of methyl orange dye from aqueous solution

Response and Revision made by Author(s)

Reviewer \#1:

\begin{tabular}{|r|l|l|}
\hline No & \multicolumn{1}{|c|}{ Comments } & \multicolumn{1}{|c|}{ Revision/Changes } \\
\hline 1 & Interesting article & Thank you \\
\hline 2 & & \\
\hline 3 & & \\
\hline 4 & & \\
\hline 5 & & \\
\hline 6 & & \\
\hline & & \\
\hline
\end{tabular}

\section{Reviewer \#2:}

\begin{tabular}{|r|l|l|}
\hline No & \multicolumn{1}{|c|}{ Comments } & \multicolumn{1}{c|}{ Revision/Changes } \\
\hline 1 & $\begin{array}{l}\text { Please switch the position of the last } \\
\text { paragraph (MO dye is an acid azo dye...) in } \\
\text { the introduction with the last-two paragraph } \\
\text { (In this study, we report the synthesis...). }\end{array}$ & $\begin{array}{l}\text { Done. } \\
\text { In Introduction (Part 1), paragraphs 4 switched } \\
\text { with paragraph 3. }\end{array}$ \\
\hline 2 & $\begin{array}{l}\text { Please identify the structure of each of the } \\
\text { crystal in the diffractogram and give each } \\
\text { plane in the diffractogram the } \\
\text { corresponding indices. }\end{array}$ & $\begin{array}{l}\text { Done. } \\
\text { In Results and discussion, Part 3.1, first } \\
\text { paragraph did mentioned about crystal structure } \\
\text { and planes were indices in Fig. 3. }\end{array}$ \\
\hline 3 & & \\
\hline 4 & & \\
\hline 5 & & \\
\hline 6 & & \\
\hline
\end{tabular}

